\title{
Bufalin suppresses cancer stem-like cells in gemcitabine- resistant pancreatic cancer cells via Hedgehog signaling
}

\author{
HAIYONG WANG ${ }^{1,2}$, ZHOUYU NING ${ }^{1,2}$, YINGYI LI ${ }^{2,3}$, XIAOYAN ZHU ${ }^{1,2}$ and ZHIQIANG MENG ${ }^{1,2}$ \\ ${ }^{1}$ Department of Integrative Oncology, Fudan University Shanghai Cancer Center; ${ }^{2}$ Department of Oncology, \\ Shanghai Medical College, Fudan University; ${ }^{3}$ Department of Molecular Biology, Cancer Research Institute, \\ Fudan University Shanghai Cancer Center, Shanghai 200032, P.R. China
}

Received April 19, 2015; Accepted March 29, 2016

DOI: $10.3892 / \mathrm{mmr} .2016 .5471$

\begin{abstract}
Cancer stem cells (CSCs) are important in cancer, as these cells possess enhanced tumor-forming capabilities and are resistant to current anticancer therapies. Agents with the ability to suppress CSCs are likely to provide novel opportunities for combating tumor proliferation and metastasis. The present study aimed to evaluate the effects of bufalin on pancreatic CSCs in vivo and in vitro. Using a serum-free suspension culture, tumor spheres were enriched in a gemcitabine-resistant human pancreatic cancer cell line, which had a higher percentage of CSCs, and western blotting, flow cytometry, and colony and tumor formation assays were used to demonstrate that these sphere cells exhibited CSC characteristics. Using these cancer stem-like cells as a model, the present study examined the effect of bufalin on pancreatic CSCs. It was demonstrated that bufalin inhibited the number of tumor spheres, and western blotting and immunohistochemical assays showed that the expression levels of CD24 and epithelial specific antigen (ESA) were downregulated by bufalin. Furthermore, in a subcutaneous xenograft model of implanted gemcitabine-resistant MiaPaCa2 cells, bufalin inhibited tumor growth and prolonged the duration of tumor formation. Additionally, the expression levels of CD24 and ESA were inhibited in the bufalin-treated mice. Notably, in another cancer model injected with tumor cells via the tail vein, fewer metastatic lesions were detected in the group in which tumor cells were pretreated with bufalin in vitro, compared with those without pretreatment. Of note, the Hedgehog (Hh) signaling pathway was found to be inhibited in the bufalin-treated cells. Taken together, these results suggested that bufalin suppressed pancreatic CSCs in gemcitabine-resistant $\mathrm{MiaPaCa} 2$ cells, and the Hh signaling pathway may be involved in this process.
\end{abstract}

Correspondence to: Dr Xiaoyan Zhu or Dr Zhiqiang Meng, Department of Integrative Oncology, Fudan University Shanghai Cancer Center, 270 Dong An Road, Shanghai 200032, P.R. China

E-mail: zhuxiaoyanx@126.com

E-mail: mengzhq@gmail.com

Key words: bufalin, cancer stem like-cells, pancreatic cancer

\section{Introduction}

Pancreatic cancer is the fourth leading cause of cancer-associated mortality worldwide and has an overall 5-year survival rate of $<5 \%$ (1). In $90 \%$ of patients, the disease is surgically unresectable at diagnosis, and the majority of patients who undergo resection for localized lesions develop recurrent or metastatic disease (2). Therefore, it is important to develop novel therapeutic strategies in order to combat resistance and metastasis.

Cancer stem cells (CSCs) are cells that have the capacity to generate the heterogeneous cancer cell lineages found in tumors and possess the capacity for self-renewal (3). Other important attributes of CSCs include active telomerase expression, resistance to harmful drugs/agents, activation of anti-apoptotic pathways, the ability to migrate and to metastasize, and increased membrane transporter activity (3). It has been demonstrated that solid tumors contain a subpopulation of CSCs (4), which cannot be eradicated by current therapeutic strategies and are responsible for tumor relapse and metastasis (5). In pancreatic cancer, there are typically $0.2-0.8 \%$ CSCs, which are considered responsible for tumor growth, invasion, metastasis and recurrence (6). In particular, CD44, CD24 and epithelial specific antigen (ESA) have been used as separation markers to identify populations of pancreatic CSCs (7). However, reports on treatment targeting CSCs in pancreatic cancer are limited.

Hedgehog (Hh) signaling is key in CSC biology and may be used a potential therapeutic target in pancreatic cancer $(8,9)$. A previous study highlighted the involvement of the Hh signaling pathway in pancreatic tumorigenesis; inhibition of the pathway and pluripotency maintaining factors regulated human pancreatic cancer stem cell characteristics (10). Furthermore, it has been reported that pharmacological blockade of aberrant Hh signaling may prove to be an effective therapeutic strategy for the inhibition of systemic metastases in pancreatic cancer, likely via targeting CSCs (11).

Bufalin is a toad poison ligand extracted from toad cake, which is a type of traditional Chinese medicine (12). Bufalin has been shown to be a potential anticancer agent in various cancer models (13-16). However, the effects of bufalin on CSCs have not been examined in a model of pancreatic cancer. The present study aimed to evaluate the effects of bufalin on pancreatic CSCs in vivo and in vitro. 


\section{Materials and methods}

Reagents and antibodies. Bufalin and dimethyl sulfoxide were obtained from Sigma-Aldrich (St. Louis, MO, USA). Rabbit anti-CD44 polyclonal antibody $(1: 1,000$; cat. no. BS6825) and horseradish peroxidase (HRP)-conjugated goat anti-rabbit IgG (1:10,000; cat. no. BS13287) were purchased from Bioworld Technology (Minneapolis, MN, USA). Rabbit anti-ESA polyclonal antibody $(1: 1,000$; cat. no. 21050-1-AP) was purchased from Proteintech Group, Inc. (Wuhan, China). Phycoerythrin-conjugated mouse antiCD44 monoclonal antibody (1:100; cat. no. 130-095-180), allophycocyanin-conjugated mouse anti-CD24 monoclonal antibody (1:100; cat. no. 130-095-954), and fluorescein isothiocyanate (FITC)-conjugated mouse anti-ESA monoclonal antibody (1:100; cat. no. 130-080-301) for flow cytometry were purchased from Miltenyi Biotec $\mathrm{GmbH}$ (Bergisch Gladbach, Germany). Rabbit anti-Patched (PTCH)1 monoclonal antibody (1:1,000; cat. no. 2468), PTCH2 polyclonal antibody (1:1,000; cat. no. 2464), glioma-associated oncogene 1 (Gli1) monoclonal antibody $(1: 1,000$; cat. no. 3538$)$ and GAPDH monoclonal antibody (1:1,000; cat. no. 8884) were purchased from Cell Signaling Technology, Inc. (Beverly, MA, USA).

Cell culture and serum-free suspension culture for enrichment of pancreatic CSCs. The human pancreatic cancer gemcitabine-resistant cell line, $\mathrm{MiaPaCa} 2 / \mathrm{GEM}$, was provided by Professor Yingyi Li from The Cancer Research Institute, Fudan University Shanghai Cancer Center (Shanghai, China). The MiaPaCa2/GEM cell line was cultured in Dulbecco's modified Eagle's medium (DMEM) containing 10\% fetal bovine serum (FBS; Gibco; Thermo Fisher Scientific, Inc., Waltham, MA, USA) and $5 \% \mathrm{CO}_{2}$ at $37^{\circ} \mathrm{C}$. For CSCs, the $\mathrm{MiaPaCa} / \mathrm{GEM}$ cells were washed three times for $5 \mathrm{~min}$ each with phosphate-buffered saline (PBS) repeatedly, after which the cells $\left(2 \times 10^{3}\right)$ were resuspended in tumor stem medium consisting of serum-free neural stem cell medium, epidermal growth factor $(20 \mathrm{ng} / \mathrm{ml})$, basic fibroblast growth factor $(20 \mathrm{ng} / \mathrm{ml})$, leukemia inhibitory factor $(1,000 \mathrm{U} / \mathrm{ml})$, and 15\% knockout serum replacement (Gibco; Thermo Fisher Scientific, Inc.) and cultured in an ultra-low adhesion dish.

Cell proliferation array and colony formation assay. Cell proliferation analysis was performed, as described previously (17). Briefly, the cells were plated at a density of 5,000 cells per well in 96-well microtiter plates, and incubated overnight at $37^{\circ} \mathrm{C}$ in a humidified incubator containing $5 \% \mathrm{CO}_{2}$. On the following day, various concentrations of bufalin $(10,50,100,500$ or $1,000 \mathrm{nM})$ were added to the wells, and the cultures were incubated for an additional 24,48 or $72 \mathrm{~h}$ at $37^{\circ} \mathrm{C}$. Cell viability was determined using a Cell Counting Kit-8 (Dojindo, Gaithersburg, MD, USA), according to the manufacturer's protocol. For the colony formation assays, $2 \times 10^{3} \mathrm{MiaPaCa} / \mathrm{GEM}$ cells or sphere cells were plated in 6 -well plates and cultured with 10\% FBS DMEM. The culture medium was replaced every 3 days. After 2 weeks, the colonies were fixed with $4 \%$ paraformaldehyde and stained with $0.1 \%$ crystal violet (both Sangon Biotech Co., Ltd., Shanghai, China), and images of the colonies were captured using the
Epson Perfection V600 Photo scanner digital camera (Seiko Epson Corporation, Suwa, Japan).

Flow cytometry. The cell suspension was centrifuged at $300 \mathrm{x} \mathrm{g}$ for $10 \mathrm{~min}$ at $4^{\circ} \mathrm{C}$ and the cells $\left(1 \times 10^{7}\right.$ nucleated cells) were resuspended in $100 \mu \mathrm{l}$ PBS. Subsequently, $10 \mu \mathrm{l}$ primary antibody was added, followed by mixing and incubation for $10 \mathrm{~min}$ in the dark at $4^{\circ} \mathrm{C}$. The cells were washed by adding $1-2 \mathrm{ml}$ buffer and centrifuging at $300 \mathrm{xg}$ for $10 \mathrm{~min}$. The cell pellet was then resuspended in $500 \mu 1 \mathrm{PBS}$ for analysis by flow cytometry (Cytomics FC 500 Flow Cytometer; Beckman Coulter, Inc., Brea, CA, USA).

Western blot analysis. The cells were washed with cold PBS and lysed in culture dishes using PhosphoSafe ${ }^{\mathrm{TM}}$ extraction reagent (Merck Millipore, Darmstadt, Germany) containing $1 \%$ protease inhibitor cocktail (EDTA-free; Thermo Fisher Scientific, Inc.). Protein concentrations were then determined using Bio-Rad detergent-compatible protein assays (Bio-Rad Laboratories, Inc., Hercules, CA, USA). A total of $30 \mu \mathrm{g}$ protein from the control and treated cell lysates, respectively were loaded onto $8-12 \%$ gradient NuPAGE gels (Novex, San Diego, CA, USA), followed by electrophoresis under reducing conditions and subsequent transfer onto polyvinylidene difluoride membranes (0.22 $\mu \mathrm{m}$; Merck Millipore). Western blot analysis was performed, as described previously (17). Briefly, the membranes were incubated overnight at $4^{\circ} \mathrm{C}$ with anti-CD44, anti-ESA, anti-PTCH1, anti-PTCH2, anti-Gli1 and anti-GAPDH primary antibodies, followed by incubation with HRP-conjugated goat anti-rabbit IgG. Blots were then developed with the SuperSignal West Femto Maximum Sensitivity Substrate (Thermo Fisher Scientific, Inc.) on a LAS-3000 Imaging system (Fujifilm, Tokyo, Japan). Band intensities were analyzed using Quantity One 4.6.6 software (Bio-Rad Laboratories, Inc.)

Animal models and treatment. Female 6-week-old BALBc nu/nu mice were obtained from the Shanghai Institute of Material Medica, Chinese Academy of Science (Shanghai, China). All mice were bred in laminar flow cabinets under pathogen-free conditions. The mice were housed individually in plastic cages at $25^{\circ} \mathrm{C}$ and under a 12-h light/dark cycle, with ad libitum access to food and water. The present study was performed in accordance with internationally recognized guidelines on animal welfare (http://www.aaalac. org/resources/theguide.cfm). The study design was approved by the Animal Ethical Committee of Fudan University (Shanghai, China).

The MiaPaCa2/GEM cells $\left(2 \times 10^{5}\right)$ were subcutaneously inoculated into the right flanks of the 6-week-old BALBc $\mathrm{nu} / \mathrm{nu}$ female mice, and treatment commenced the following day. The mice were randomly separated into two groups, with six mice in each group. The mice in the experimental group received intraperitoneal injections of $1.5 \mathrm{mg} / \mathrm{kg}$ bufalin (5 days/week), whereas the control mice were injected with vehicle (20 $\mu 1$ saline) alone. Treatment continued for 4 weeks, after which the mice were sacrificed by overdose with anesthesia ( $4 \mathrm{ml} / \mathrm{kg}$ body weight of $10 \%$ chloral hydrate), and tumors were excised from each mouse, weighed and snap-frozen for further analysis. 
A

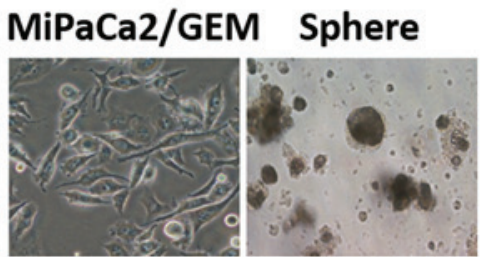

B

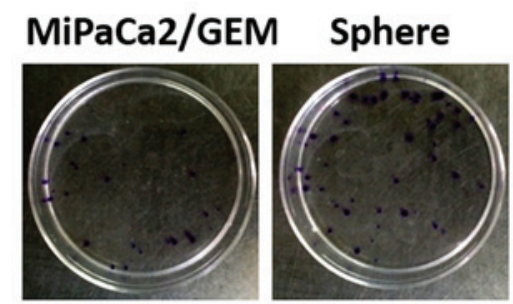

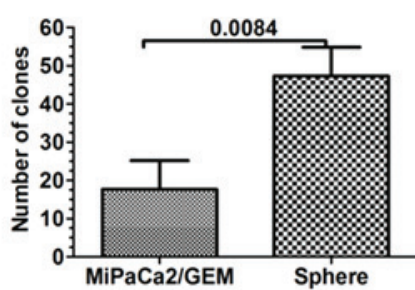

C

\begin{tabular}{|c|c|c|c|}
\hline \multirow{2}{*}{ MiPaCa2/GEM } & \multicolumn{3}{|c|}{ Tumor Seeding } \\
\hline & $\begin{array}{c}\text { Cells } \\
\text { injected }\end{array}$ & $\begin{array}{l}\text { MiPaCa } \\
\text { 2/GEM }\end{array}$ & Sphere \\
\hline \multirow{2}{*}{ Sphere } & $1 \times 10^{6}$ & $3 / 3$ & $3 / 3$ \\
\hline & $1 \times 10^{5}$ & $2 / 3$ & $3 / 3$ \\
\hline \multirow[t]{2}{*}{$10^{5}-1$} & $1 \times 10^{4}$ & $0 / 3$ & $2 / 3$ \\
\hline & $1 \times 10^{3}$ & $0 / 3$ & $0 / 3$ \\
\hline
\end{tabular}

D
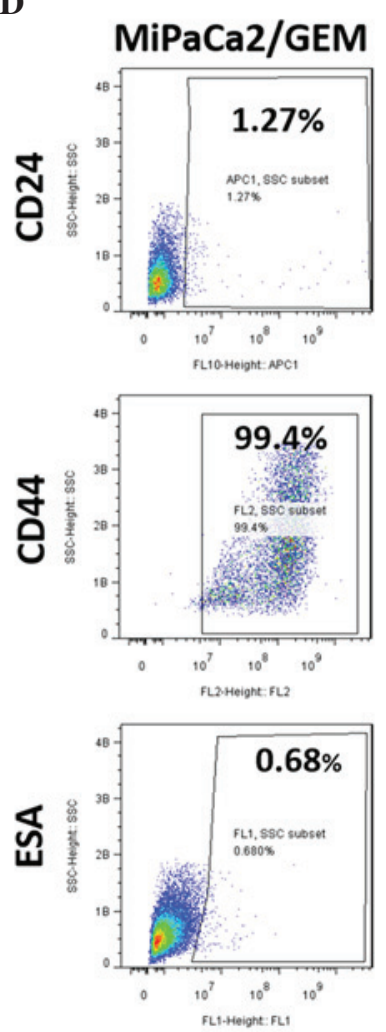
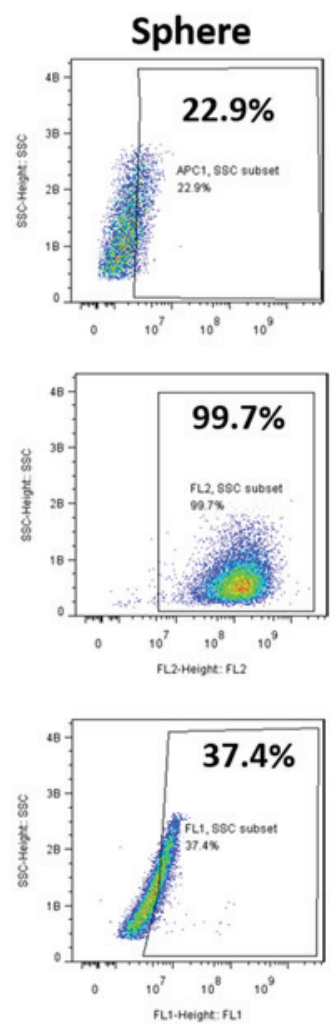

$\mathbf{E}$

MiPaCa2/GEM Sphere

CD44

ESA

GAPDH

$\mathbf{F}$

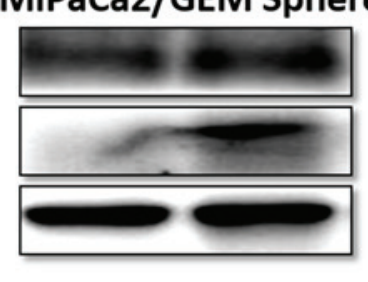

Sphere

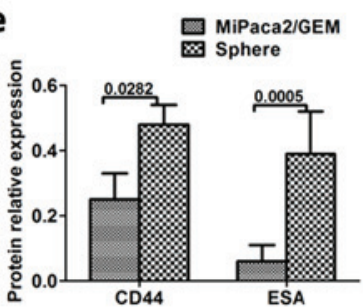

Differentiation
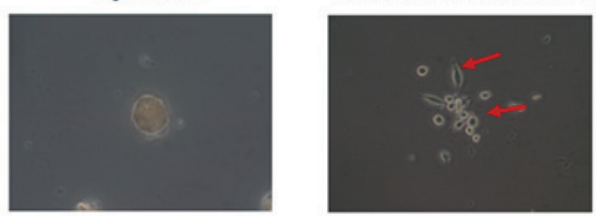

Figure 1. Successful enrichment of pancreatic CSCs using serum-free suspension culture. (A) Pancreatic cancer stem-like cell sphere enrichment by serum-free suspension culture (magnification, x200). (B) Clone formation of sphere and MiaPaCa2/GEM cells using a colony formation assay; the bar graph shows the numbers of clones in each group. Data are expressed as the mean \pm standard deviation. (C) Tumor formation rate in mice implanted with different densities of sphere cells or MiaPaCa2/GEM cells. The red arrows indicate the tumor. Data are presented as the number of tumors formed/number of mice injected. (D) Flow cytometry was used to determine the expression levels of CD24, CD44 and ESA in the sphere cells and MiaPaCa2/GEM cells. (E) Western blotting and densitometric analyses were used to determine the expression levels of CD44 and ESA in the sphere cells and MiaPaCa2/GEM cells. (F) Representative images of the sphere cells and differentiated cells (magnification, x200). CSC, cancer stem cell; ESA, epithelial specific antigen.

In addition, mice were randomly divided into another two groups, with six mice in each group, in which MiaPaCa2/GEM cells $\left(2 \times 10^{6} / 0.2 \mathrm{ml} \mathrm{PBS}\right)$, which were pretreated with bufalin in one of the groups, were injected via the tail veins of the female mice. The mice were sacrificed after 6 weeks. The intestinal tissues and lung tissues were excised from each mouse for further analysis.

Immunohistochemistry. Immunohistochemical analysis was performed, as described previously (18). Briefly, the tumor sections were stained with rabbit anti-ESA at $4^{\circ} \mathrm{C}$ overnight. Goat anti-rabbit or mouse IgG/HRP was applied as the secondary antibody, according to the standard protocols provided by the manufacturer. For negative controls, the primary antibodies were replaced with PBS. Immunopositivity was assessed by two independent investigators, who were blinded to the model/treatment type for the series of experiments. The tumor sections were counterstained for $1 \mathrm{~min}$ with hematoxylin.
Immunofluorescence. The tumor sections were stained with rabbit anti-CD24 (1:50) at $4^{\circ} \mathrm{C}$ overnight. Following washing with PBS, the tumor sections were subsequently incubated with fluorescence-conjugated secondary antibody for $2 \mathrm{~h}$ at $37^{\circ} \mathrm{C}$. The sections were then mounted with mounting medium containing DAPI (Vector Laboratories). For negative controls, primary antibodies were replaced with PBS. Images were captured using a confocal fluorescence microscope (Leica Microsystems GmbH, Wetzlar, Germany).

Statistical analysis. All analyses of results were performed using GraphPad prism version 5.0 (GraphPad Software, San Diego, CA, USA) and the SPSS 19.0 software package (IBM SPSS, Armonk, NY, USA). Statistical analyses were performed using $\chi^{2}$ tests, Student's $t$-test and one-way analysis of variance models. $\mathrm{P}<0.05$ was considered to indicate a statistically significant difference. 
A

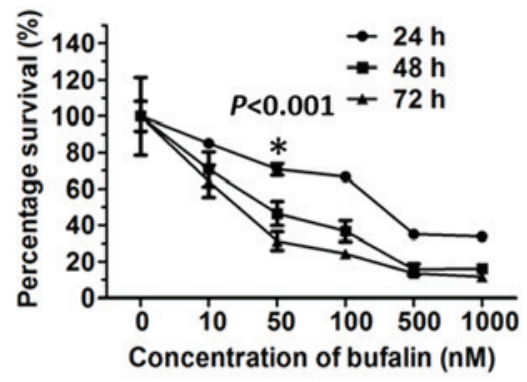

C
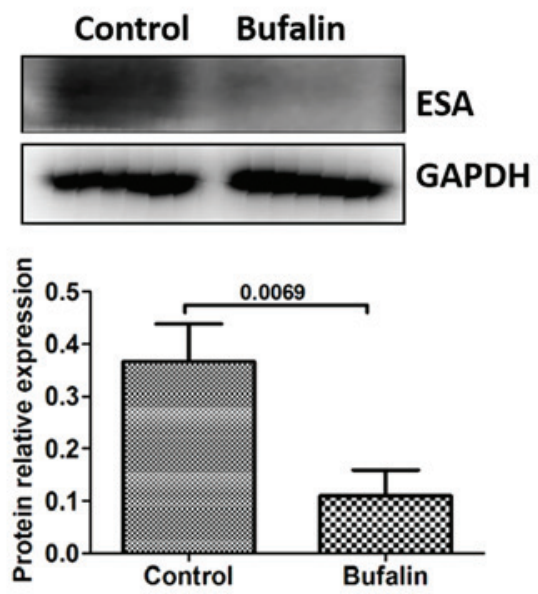

B Control
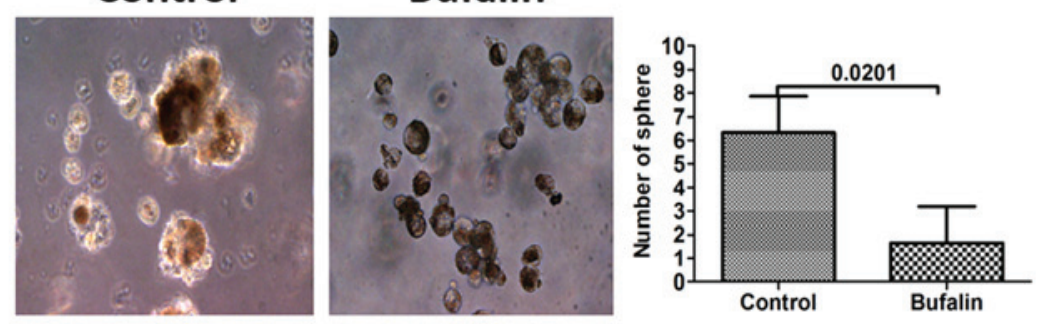

D

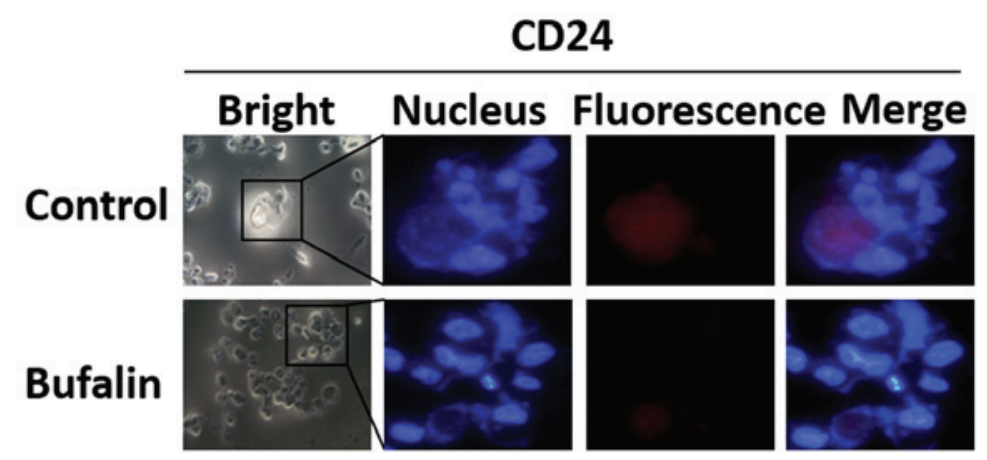

Figure 2. Bufalin inhibits pancreatic CSCs in vitro. (A) Cells were seeded into a 96-well plate and treated with various concentrations of bufalin; viability was measured using a Cell Counting kit-8 assay. (B) Representative images of pancreatic CSC spheres in the control and bufalin pretreated groups (magnification, $\mathrm{x} 400)$. The bar graph shows the mean number of spheres ( \pm standard deviation) in each group, calculated from three independent experiments. (C) Western blot and densitometric analyses were used to measure the expression levels of the CSC-associated marker, ESA. GAPDH was used as a loading control. Data are presented as the mean \pm standard deviation ( $n=3$ ). (D) Immunofluorescence was used to measure the expression levels of the CSC-associated marker, CD24 (magnification, $\mathrm{x} 400$ ). CSC, cancer stem cell; ESA, epithelial specific antigen.

\section{Results}

Enrichment of pancreatic CSCs using serum-free suspension culture. The isolation of CSCs from cancer cells has been successfully achieved via the use of serum-free suspension culture, and sphere-forming assays also have been used to identify cancer stem cells (19). In the present study, the MiaPaCa2/GEM cell line exhibited a higher proportion of CSCs, and pancreatic cancer stem cell spheres were successfully cultured using serum-free suspension culture (Fig. 1A). To determine whether these sphere cells were CSCs, colony formation and tumor formation assays were used to identify stem cell properties. The MiaPaCa2/GEM cells and the sphere cells $\left(1 \times 10^{3} / \mathrm{ml}\right)$ were resuspended and seeded into a $6 \mathrm{~cm}$ dish $(2 \mathrm{ml})$. After 2 weeks, more clones were detected in the sphere cell group (Fig. 1B). The tumor formation assay revealed that sphere cell densities of $1 \times 10^{5}$ and $1 \times 10^{4}$ were sufficient to induce tumor formation in the nude mice, and more tumor formation was observed, compared with the same density of control cells. In particular, no tumor formation was observed in the control mice implanted with $1 \times 10^{4} \mathrm{MiaPaCa} 2 / \mathrm{GEM}$ cells (Fig. 1C). Studies have demonstrated that CD44, CD24 and ESA have been used as separation markers to identify a population of pancreatic CSCs $(7,20,21)$. Therefore, western blotting and flow cytometry were performed, which revealed that the sphere cells had higher expression levels of CD24, CD44 and ESA (Fig. 1D and E). Notably, when the sphere cells were cultured in the adhesive culture system with normal medium, they differentiated into MiaPaCa2/GEM cells (Fig. 1F). Taken together, these results demonstrated the successful enrichment of pancreatic CSCs using serum-free suspension culture.

Bufalin inhibits pancreatic CSCs in vitro. The present study examined whether bufalin had an effect on the viability of CSCs in vitro. A cell proliferation assay was used to measure the effects of bufalin on the proliferative capability of the pancreatic cancer cells. MiaPaCa2/GEM cells were treated with bufalin $(10,50,100,500$ or 1,000 nM) for 24,48 or $72 \mathrm{~h}$. Bufalin was observed to have an anti-proliferative effect on the $\mathrm{MiaPaCa}$ /GEM cells, which was dose- and time-dependent at concentrations between 10 and $1,000 \mathrm{nM}$ (Fig. 2A). The maximum nontoxic concentration of bufalin was $50 \mathrm{nM}$ and the most pronounced inhibition of CSCs occurred after $24 \mathrm{~h}$, without toxicity. Therefore, a bufalin concentration of $50 \mathrm{nM}$ and a treatment duration of $24 \mathrm{~h}$ were applied for the subsequent experiments. The MiaPaCa2/GEM cells were pretreated with $50 \mathrm{nM}$ bufalin for $24 \mathrm{~h}$, and the subsequent sphere formation arrays detected fewer sphere cells in the bufalin-pretreated group (Fig. 2B). The markers of pancreatic CSCs were further examined to determine the effect of bufalin on the CSCs. As expected, the expression levels of CD24 and ESA were downregulated, demonstrated using Western blot analysis and immunofluorescence (Fig. 2C and D). 
A

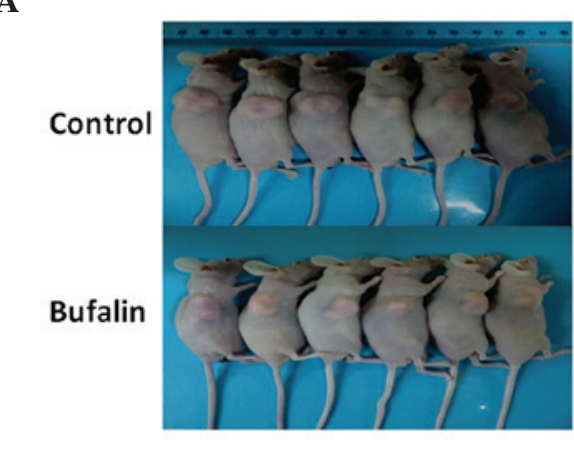

C

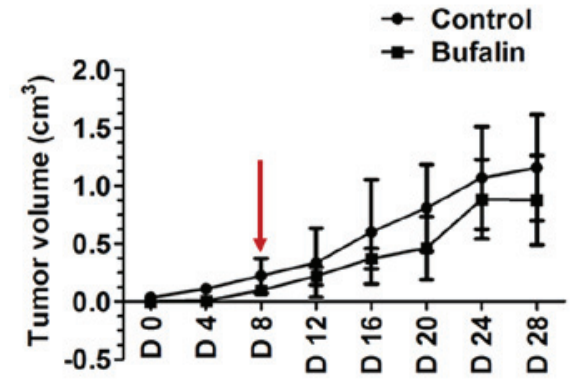

B Control
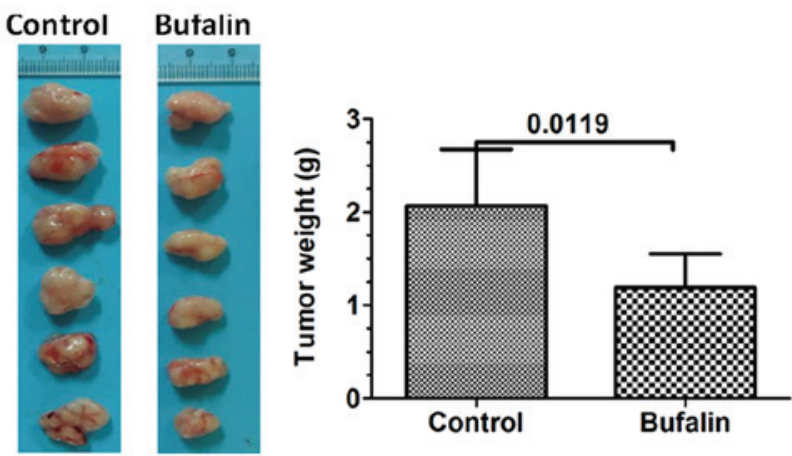

D

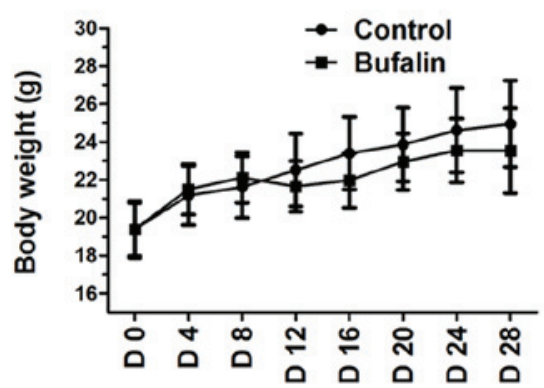

Figure 3. Bufalin inhibits the growth of pancreatic tumors in vivo. Mice were subcutaneously implanted with MiaPaCa2/GEM cells and treated with bufalin $(1.5 \mathrm{mg} / \mathrm{kg} ; 5$ days/week) via intraperitoneal injection for 4 weeks. (A and B) Images of subcutaneous transplanted tumors from the control and bufalin-treated groups; the bar graph shows the tumor weights in the groups. (C) Tumor volumes in the two groups. (D) No significant difference in body weight was found between the control and bufalin-treated mice. Data are expressed as the mean \pm standard deviation $(n=6)$. CSC, cancer stem cell; $D$, day.

A
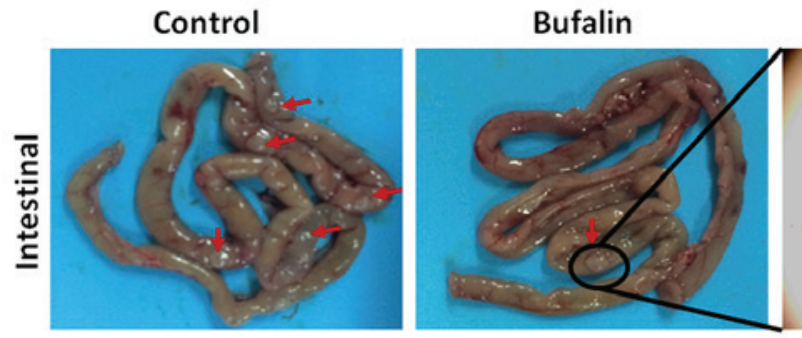

H\&E

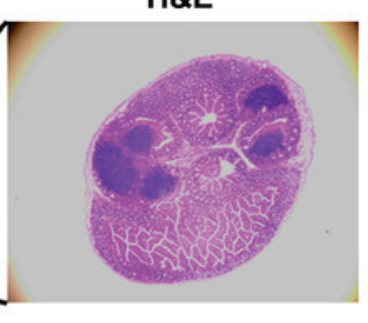

B

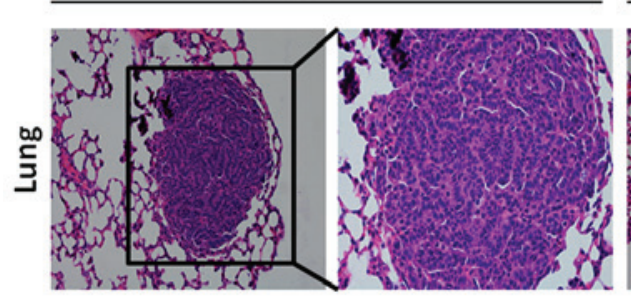

Bufalin
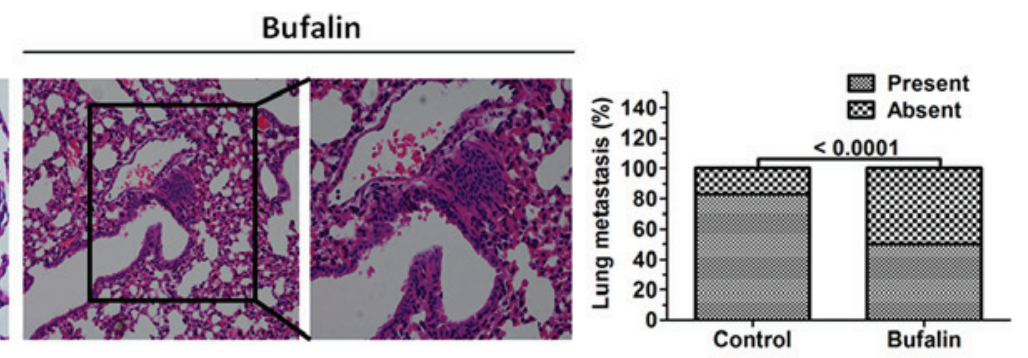

C

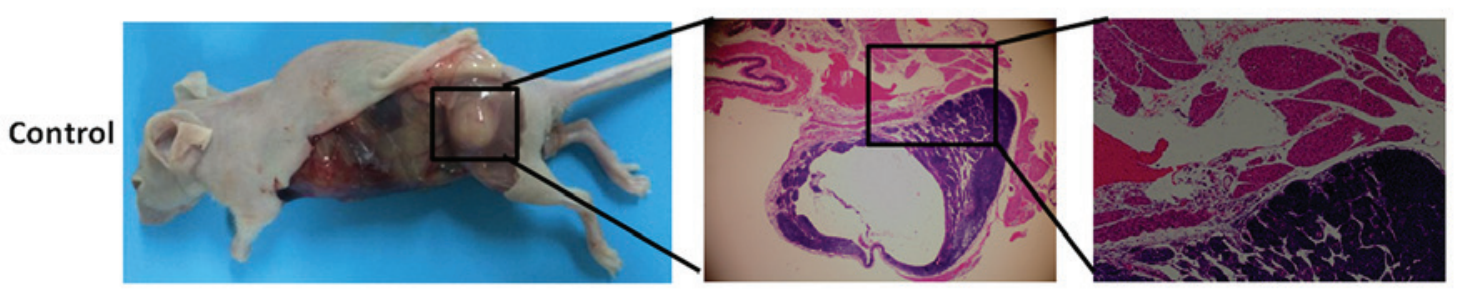

Figure 4. Bufalin inhibits systemic metastasis of MiaPaCa2/GEM cells in vivo. A systemic metastasis model was established by injecting mice with MiaPaCa2/GEM cells pretreated with bufalin via the tail vein. (A) Representative images of intestinal metastasis. The red arrows indicate intestinal tumor lesions. Fewer intestinal lesions were observed in the bufalin-treated group. H\&E staining was used to visualize the intestinal tumor lesion in the bufalin-treated mice under a microscope (magnification, x200). The bar graph shows the number of intestinal metastases in each group. Data are expressed as the mean \pm standard deviation ( $n=6)$. (B) Representative images showing H\&E staining (left: magnification, $x 200$; right: magnification, $\mathrm{x} 400$ ), to detect lung metastasis in the control and bufalin-treated mice. The bar graph shows the percentage of MiaPaCa2/GEM cell injections that resulted in lung metastases. (C) Representative images of muscle metastasis; H\&E staining was used to confirm metastasis to the muscles (magnification, x200). CSC, cancer stem cell; H\&E, hematoxylin and eosin. 
A

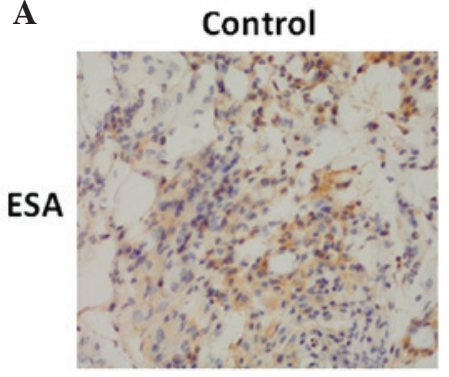

B

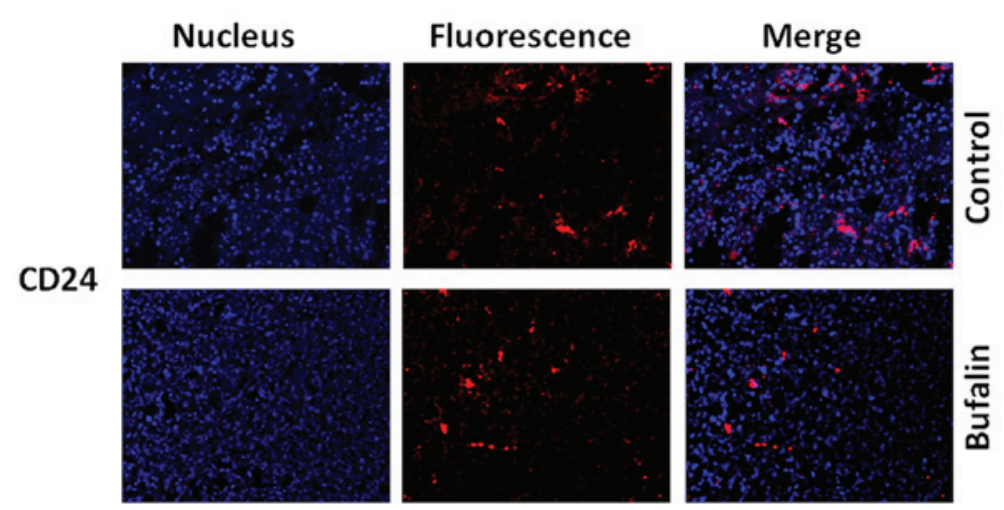

Bufalin

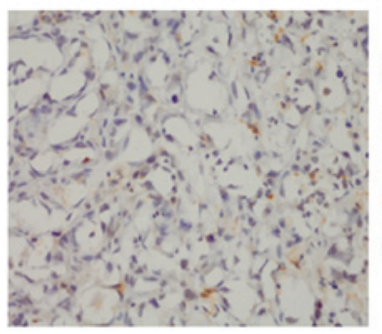

Fluorescence

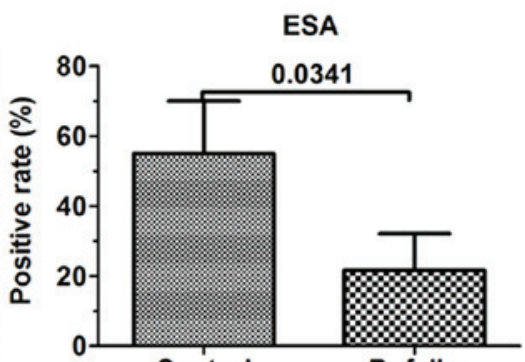

Bufalin

Figure 5. Bufalin downregulates the expression levels of CD24 and ESA. In the subcutaneous xenograft model, the control and bufalin-treated tumors were excised and analyzed using immunohistochemistry and/or immunofluorescence to measure the expression levels of CSC-associated markers. (A) Immunohistochemical staining with anti-ESA was performed using sections of subcutaneous xenograft; the positive rate of the CSC-associated marker, ESA, was determined based on the immunohistochemistry. Data are expressed as the mean + standard deviation ( $\mathrm{n}=6)$. (B) Expression levels of CD24 was assessed using immunofluorescence. CSC, cancer stem cell; ESA, epithelial specific antigen.

A

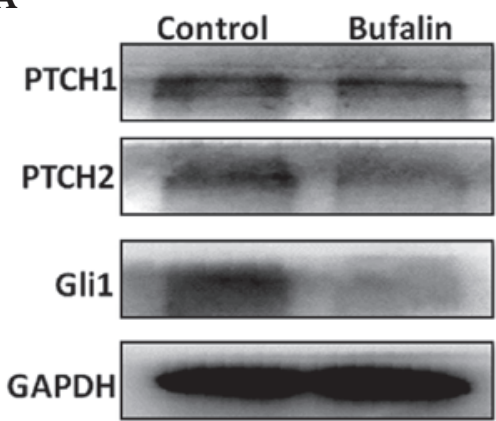

B

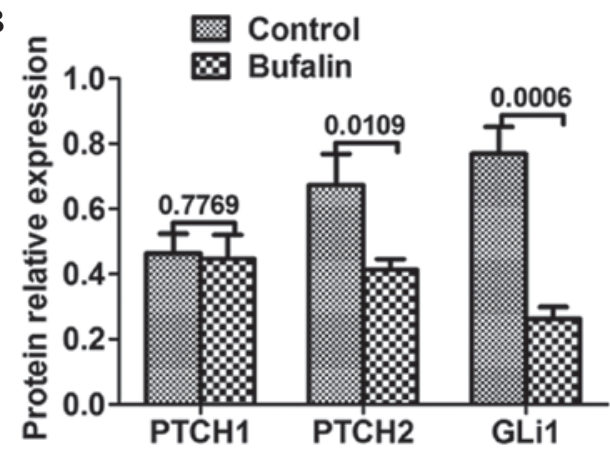

Figure 6. Bufalin inhibits the Hedgehog signaling pathway in vitro. (A) Western blot analysis was used to measure the expression levels of PTCH1, PTCH2 and Gli1. GAPDH was used as a loading control. (B) Densitometric analysis of three independent experiments with three replicates per experiment. Data are presented as the mean \pm standard deviation. PTCH1, Patched 1; PTCH2, Patched 2; Gli1, glioma-associated oncogene 1.

Bufalin inhibits the growth of pancreatic tumors following MiaPaCa2/GEM cell implantation. The present study also evaluated the effect of bufalin on tumor growth in nude mice using MiaPaCa2/GEM cells. The results showed that bufalin reduced subcutaneous xenograft growth, compared with the control tumors (Fig. 3A and B). Tumors were not detected until day 8 in the bufalin-treated mice (Fig. 3C). Additionally, bufalin treatment was well tolerated by the mice, as no weight loss or signs of acute or delayed toxicity were observed (Fig. 3D).

Bufalin inhibits systemic metastasis of MiaPaCa2/GEM cells in vivo. As is already known, CSCs have the ability to migrate and to metastasize (3). In the present study, MiaPaCa2/GEM cells were injected into mice, which had either been pretreated with $50 \mathrm{nM}$ bufalin for $24 \mathrm{~h}$ via their tail veins or received no pretreatment, and systemic metastasis was examined. The results showed that fewer intestinal tumor lesions were detected in the bufalin-pretreated mice (Fig. 4A). Of note, fewer mice had metastatic lung lesions in the bufalin-pretreated group (Fig. 4B). A single mouse in the non-pretreated control group formed metastatic lesions in the muscle (Fig. 4C).

Bufalin downregulates the expression levels of CD24 and ESA. As the expression levels of CD24 and ESA were downregulated in vitro. Immunohistochemical and immunofluorescence staining was also used to evaluate the expression levels of CD24 and ESA in vivo. The results demonstrated that the expression levels of CD24 and ESA were also inhibited in the tumor tissues of the bufalin group (Fig. 5). 
Bufalin inhibits the Hh signaling pathway in vitro. The $\mathrm{Hh}$ signaling pathway is important in pancreatic CSCs (22). In the present study, Western blot analysis was used to evaluate the expression levels of $\mathrm{Hh}$ signaling proteins. As expected, the expression levels of PTCH2 and Gli1 were downregulated in the bufalin-pretreated group. No significant change was observed in the expression of PTCH1 (Fig. 6).

\section{Discussion}

In the present study, the effect of bufalin on pancreatic CSCs was investigated in vivo and in vitro. Firstly, pancreatic CSCs were successfully enriched by serum-free suspension culture in a gemcitabine-resistant pancreatic cancer cell line. Using this CSC model, the results showed that bufalin inhibited the proportion of pancreatic CSCs, and downregulated the levels of CD24 and ESA. Notably, bufalin inhibited tumor growth and extended tumor formation duration, in addition to downregulating the levels of CD24 and ESA in a subcutaneous xenograft model established via MiaPaCa2/GEM cell implantation. In another tumor metastasis model, in which tumor cells were injected into mice via the tail vein, fewer tumor metastasis was detected in the bufalin-pretreated group, demonstrating that pancreatic CSCs may be inhibited in bufalin-pretreated pancreatic cancer cells.

CSCs can be isolated by different methods, using surface markers of CSCs (23-25), Hoechst dye efflux (26) and sphere culture using serum-free suspension culture (19). The isolation of CSCs based on surface markers is the most commonly used method. However, the percentage of CSCs is only $~ 0.2-0.8 \%$ in pancreatic cancer cell lines (6), therefore, this method is difficult to perform and is time-consuming. In the present study, the MiaPaCa2/GEM gemcitabine-resistant pancreatic cancer cell line was used to isolate the pancreatic CSCs. Following this, serum-free suspension culture was used to enrich pancreatic CSC sphere cells. The colony formation assay and tumor formation assay demonstrated that these sphere cells exhibited CSC properties. The cell surface markers were examined further using Western blot analysis and flow cytometry, and the stem cell-like properties of the sphere cells were further affirmed.

Pancreatic cancer is typically diagnosed in the late stages, in which most patients are inoperable, and curable treatment is not available. Radiotherapy and chemotherapy may improve prognosis and reduce tumor size, but cannot target all pancreatic cancer cells $(27,28)$. Studies have demonstrated that CSCs may be the reason underlying the inability to eradicate pancreatic cancer using current therapeutic techniques, and thus are responsible for tumor relapse and metastasis (6,29-32). CSCs have been isolated and characterized in pancreas cancer. Li et al (7) were the first to identify a population of pancreatic CSCs using CD44, CD24 and ESA as separation markers. In another study, CD $44^{+} / \mathrm{CD} 24^{-}$cells were isolated from a pancreatic adenocarcinoma cell line, and these cells exhibited a markedly higher tumorigenic potential, compared with cellular subpopulations, which did not express these markers (33). In the present study, the expression levels of CD24 and ESA were markedly higher in the sphere cells, as compared with the MiaPaCa2/GEM cells. Conversely, the expression levels of CD44 were not markedly different between the sphere cells and the MiaPaCa2/GEM cells.

Bufalin has been shown to be a potential anticancer agent in various cancer models (34-36). As with other cardiac glycoside drugs, the anticancer target of bufalin is predominantly the $\mathrm{Na}^{+}-\mathrm{K}^{+}$-ATP enzyme. Bufalin exerts anticancer effects primarily by inhibiting tumor cell proliferation, and inducing tumor cell apoptosis, differentiation and triggering autophagy $(37,38)$. However, the effect of bufalin on pancreatic CSCs has not been reported. In the present study, subcutaneous tumor transplantation was performed in nude mice, which were treated the following day with bufalin or physiological saline. Tumor formation was not detected until 8 days in the bufalin-treated mice. This result suggested that bufalin downregulated the percentage of pancreatic CSCs exhibiting marked tumorigenicity. In addition, pancreatic cancer cells were pretreated with bufalin in vitro, following which pancreatic CSC sphere cells were enriched using serum-free suspension culture. The results demonstrated the formation of fewer sphere cells in the bufalin-pretreated cells. Notably, when these cells were injected into mice via the tail vein, fewer metastatic lesions were detected, compared with the non-pretreated mice.

Hh signaling is key in CSC biology, and can be used a potential therapeutic target in pancreatic cancer $(22,39)$. Hh signaling comprises effectors (Gli1 and Gli2), receptors (PTCH1, PTCH2 and Smoothened), and the Sonic hedgehog ligand. Increasing studies have focussed on targeting $\mathrm{Hh}$ signaling to inhibit pancreatic CSCs. For example, the Gli transcription factor inhibitor, GANT-61, can inhibit pancreatic CSC growth in vitro and in a NOD/SCID/IL2R $\gamma$ null mice xenograft by downregulating the expression levels of Gli1 and Gli2 (40). GDC-0449 can also inhibit pancreatic CSC proliferation and survival by inhibiting $\mathrm{Hh}$ signaling at the level of the Gli genes (41). In the present study, the expression levels of PTCH2 and Gli1 were suppressed in the bufalin-pretreated cells. Therefore, the Hh signaling pathway may be involved in the bufalin-induced suppression of the pancreatic CSC process.

In conclusion, the present study demonstrated that bufalin inhibited pancreatic tumor growth in vivo and pancreatic CSC growth in vitro. Furthermore, typical markers of CSCs, including CD24 and ESA were shown to be downregulated following treatment with bufalin in vivo. In addition, the expression levels of two important molecules involved in the Hh signaling pathway, PTCH2 and Gli1, were altered following bufalin treatment, which suggested that the $\mathrm{Hh}$ signaling pathway may be involved in bufalin-induced suppression of pancreatic CSCs.

\section{Acknowledgements}

The present study was supported by the National Natural Science Foundation of China (grant no.81102847).

\section{References}

1. Pandol S, Gukovskaya A, Edderkaoui M, Dawson D, Eibl G and Lugea A: Epidemiology, risk factors, and the promotion of pancreatic cancer: Role of the stellate cell. J Gastroenterol Hepatol 27 (Suppl 2): S127-S134, 2012. 
2. Onkendi EO, Boostrom SY, Sarr MG, Farnell MB, Nagorney DM, Donohue JH, Kendrick ML, Reid-Lombardo KM, Harmsen WS and Que FG: 15-year experience with surgical treatment of duodenal carcinoma: A comparison of periampullary and extra-ampullary duodenal carcinomas. J Gastrointest Surg 16: 682-691, 2012.

3. Tanase CP, Neagu AI, Necula LG, Mambet C, Enciu AM, Calenic B, Cruceru ML and Albulescu R: Cancer stem cells: Involvement in pancreatic cancer pathogenesis and perspectives on cancer therapeutics. World J Gastroenterol 20: 10790-10801, 2014.

4. Visvader JE and Lindeman GJ: Cancer stem cells in solid tumours: Accumulating evidence and unresolved questions. Nat Rev Cancer 8: 755-768, 2008.

5. Sureban SM, May R, Qu D, Weygant N, Chandrakesan P, Ali N, Lightfoot SA, Pantazis P, Rao CV, Postier RG and Houchen CW: DCLK1 regulates pluripotency and angiogenic factors via microRNA-dependent mechanisms in pancreatic cancer. PLoS One 8: e73940, 2013.

6. Li Y, Kong D, Ahmad A, Bao B and Sarkar FH: Pancreatic cancer stem cells: Emerging target for designing novel therapy. Cancer Lett 338: 94-100, 2013

7. Li C, Heidt DG, Dalerba P, Burant CF, Zhang L, Adsay V, Wicha M, Clarke MF and Simeone DM: Identification of pancreatic cancer stem cells. Cancer Res 67: 1030-1037, 2007.

8. Berman DM, Karhadkar SS, Maitra A, Montes De Oca R, Gerstenblith MR, Briggs K, Parker AR, Shimada Y, Eshleman JR, Watkins DN and Beachy PA: Widespread requirement for Hedgehog ligand stimulation in growth of digestive tract tumours. Nature 425: 846-851, 2003.

9. Olive KP, Jacobetz MA, Davidson CJ, Gopinathan A, McIntyre D, Honess D, Madhu B, Goldgraben MA, Caldwell ME, Allard D, et al: Inhibition of Hedgehog signaling enhances delivery of chemotherapy in a mouse model of pancreatic cancer. Science 324: 1457-1461, 2009.

10. Abetov D, Mustapova Z, Saliev T and Bulanin D: Biomarkers and signaling pathways of colorectal cancer stem cells. Tumour Biol 36: 1339-1353, 2015.

11. Wang F, Ma L, Zhang Z, Liu X, Gao H, Zhuang Y, Yang P, Kornmann M, Tian X and Yang Y. Hedgehog Signaling Regulates Epithelial-Mesenchymal Transition in Pancreatic Cancer Stem-Like Cells. J Cancer 7: 408-417, 2016.

12. Meng Z, Yang P, Shen Y, Bei W, Zhang Y, Ge Y, Newman RA, Cohen L, Liu L, Thornton B, et al: Pilot study of huachansu in patients with hepatocellular carcinoma, nonsmall-cell lung cancer, or pancreatic cancer. Cancer 115: 5309-5318, 2009.

13. Jiang Y, Zhang Y, Luan J, Duan H, Zhang F, Yagasaki K and Zhang G: Effects of bufalin on the proliferation of human lung cancer cells and its molecular mechanisms of action. Cytotechnology 62: 573-583, 2010 .

14. Jiang L, Zhao MN, Liu TY, Wu XS, Weng H, Ding Q, Shu YJ, Bao RF, Li ML, Mu JS, et al: Bufalin induces cell cycle arrest and apoptosis in gallbladder carcinoma cells. Tumour Biol 35 : 10931-10941, 2014.

15. Wu SH, Hsiao YT, Chen JC, Lin JH, Hsu SC, Hsia TC, Yang ST, Hsu WH and Chung JG: Bufalin alters gene expressions associated DNA damage, cell cycle, and apoptosis in human lung cancer NCI-H460 cells in vitro. Molecules 19: 6047-6057, 2014.

16. Chueh FS, Chen YY, Huang AC, Ho HC, Liao CL, Yang JS, Kuo CL and Chung JG: Bufalin-inhibited migration and invasion in human osteosarcoma U-2 OS cells is carried out by suppression of the matrix metalloproteinase-2, ERK, and JNK signaling pathways. Environ Toxicol 29: 21-29, 2014.

17. Gao Y, Li HX, Xu LT, Wang P, Xu LY, Cohen L, Yang PY, Gu K and Meng ZQ: Bufalin enhances the anti-proliferative effect of sorafenib on human hepatocellular carcinoma cells through downregulation of ERK. Mol Biol Rep 39: 1683-1689, 2012.

18. Wang P, Chen Z, Meng ZQ, Fan J, Luo JM, Liang W, Lin JH, Zhou ZH, Chen $\mathrm{H}$, Wang K, et al: Dual role of Ski in pancreatic cancer cells: Tumor-promoting versus metastasis-suppressive function. Carcinogenesis 30: 1497-1506, 2009.

19. Uchida S, Yokoo S, Yanagi Y, Usui T, Yokota C, Mimura T, Araie M, Yamagami S and Amano S: Sphere formation and expression of neural proteins by human corneal stromal cells in vitro. Invest Ophthalmol Vis Sci 46: 1620-1625, 2005.

20. Li C, Lee CJ and Simeone DM: Identification of human pancreatic cancer stem cells. Methods Mol Biol 568: 161-173, 2009.
21. Zhu J, He J, Liu Y, Simeone DM and Lubman DM: Identification of glycoprotein markers for pancreatic cancer CD24+CD44+ stem-like cells using nano-LC-MS/MS and tissue microarray. J Proteome Res 11: 2272-2281, 2012.

22. Kim EJ, Sahai V, Abel EV, Griffith KA, Greenson JK, Takebe N, Khan GN, Blau JL, Craig R, Balis UG, et al: Pilot clinical trial of hedgehog pathway inhibitor GDC-0449 (vismodegib) in combination with gemcitabine in patients with metastatic pancreatic adenocarcinoma. Clin Cancer Res 20: 5937-5945, 2014.

23. Wright MH, Calcagno AM, Salcido CD, Carlson MD, Ambudkar SV and Varticovski L: Brcal breast tumors contain distinct $\mathrm{CD}_{4} 4^{+} / \mathrm{CD} 24^{-}$and $\mathrm{CD} 133^{+}$cells with cancer stem cell characteristics. Breast Cancer Res 10: R10, 2008.

24. Yu F, Yao H, Zhu P, Zhang X, Pan Q, Gong C, Huang Y, Hu X, Su F, Lieberman J and Song E: Let-7 regulates self renewal and tumorigenicity of breast cancer cells. Cell 131: 1109-1123, 2007.

25. Eyler CE and Rich JN: Survival of the fittest: Cancer stem cells in therapeutic resistance and angiogenesis. J Clin Oncol 26: 2839-2845, 2008

26. Hadnagy A, Gaboury L, Beaulieu R and Balicki D: SP analysis may be used to identify cancer stem cell populations. Exp Cell Res 312: 3701-3710, 2006.

27. Mizuno N, Yatabe Y, Hara K, Hijioka S, Imaoka H, Shimizu Y, Ko SB and Yamao K: Cytoplasmic expression of LGR5 in pancreatic adenocarcinoma. Front Physiol 4: 269, 2013.

28. Matsuda Y, Kure S and Ishiwata T: Nestin and other putative cancer stem cell markers in pancreatic cancer. Med Mol Morphol 45: 59-65, 2012.

29. Chefetz I, Alvero AB, Holmberg JC, Lebowitz N, Craveiro V, Yang-Hartwich Y, Yin G, Squillace L, Gurrea Soteras M, Aldo P and Mor G: TLR2 enhances ovarian cancer stem cell self-renewal and promotes tumor repair and recurrence. Cell Cycle 12: 511-521, 2013

30. Croker AK and Allan AL: Inhibition of aldehyde dehydrogenase (ALDH) activity reduces chemotherapy and radiation resistance of stem-like ALDH ${ }^{\text {hi }}$ CD $44^{+}$human breast cancer cells. Breast Cancer Res Treat 133: 75-87, 2012.

31. Rich JN: Cancer stem cells in radiation resistance. Cancer Res 67: 8980-8984, 2007.

32. Zhang Q, Shi S, Yen Y, Brown J, Ta JQ and Le AD: A subpopulation of CD133(+) cancer stem-like cells characterized in human oral squamous cell carcinoma confer resistance to chemotherapy. Cancer Lett 289: 151-160, 2010.

33. Huang P, Wang CY, Gou SM, Wu HS, Liu T and Xiong JX: Isolation and biological analysis of tumor stem cells from pancreatic adenocarcinoma. World J Gastroenterol 14: 3903-3907, 2008.

34. Jiang L, Zhao MN, Liu TY, Wu XS, Weng H, Ding Q, Shu YJ, Bao RF, Li ML, Mu JS, et al: Bufalin induces cell cycle arrest and apoptosis in gallbladder carcinoma cells. Tumour Biol 35: 10931-10941, 2014

35. Wu SH, Wu TY, Hsiao YT, Lin JH, Hsu SC, Hsia TC, Yang ST, Hsu WH and Chung JG: Bufalin induces cell death in human lung cancer cells through disruption of DNA damage response pathways. Am J Chin Med 42: 729-742, 2014.

36. Yan S, Qu X, Xu L, Che X, Ma Y, Zhang L, Teng Y, Zou H and Liu Y: Bufalin enhances TRAIL-induced apoptosis by redistributing death receptors in lipid rafts in breast cancer cells. Anticancer Drugs 25: 683-689, 2014.

37. Yin PH, Liu X, Qiu YY, Cai JF, Qin JM, Zhu HR and Li Q: Anti-tumor activity and apoptosis-regulation mechanisms of bufalin in various cancers: New hope for cancer patients. Asian Pac J Cancer Prev 13: 5339-5343, 2012.

38. Qi F, Li A, Inagaki Y, Kokudo N, Tamura S, Nakata M and Tang W: Antitumor activity of extracts and compounds from the skin of the toad Bufo bufo gargarizans Cantor. Int Immunopharmacol 11: 342-349, 2011.

39. Tang SN, Fu J, Nall D, Rodova M, Shankar S and Srivastava RK: Inhibition of sonic hedgehog pathway and pluripotency maintaining factors regulate human pancreatic cancer stem cell characteristics. Int J Cancer 131: 30-40, 2011

40. Fu J, Rodova M, Roy SK, Sharma J, Singh KP, Srivastava RK and Shankar S: GANT-61 inhibits pancreatic cancer stem cell growth in vitro and in NOD/SCID/IL2R gamma null mice xenograft. Cancer Lett 330: 22-32, 2013.

41. Singh BN, Fu J, Srivastava RK and Shankar S: Hedgehog signaling antagonist GDC-0449 (Vismodegib) inhibits pancreatic cancer stem cell characteristics: Molecular mechanisms. PLoS One 6: e27306, 2011. 